\title{
Congenital Tuberculosis
}

\author{
Nigam P Narain ${ }^{1 *}$, Rajesh Kumar ${ }^{1}$ and Sangita Narain ${ }^{2}$ \\ ${ }^{1}$ Department of Pediatrics, Patna Medical College, India \\ ${ }^{2}$ Department of Gynaecological Oncology, Patna Medical College, India \\ *Corresponding author: Nigam P Narain, Professor of Pediatrics, Department of Pediatrics, Patna Medical College, India
}

Submission: 眥 December 15, 2017; Published: 些August 13, 2018

\section{Introduction}

Tuberculosis (TB) is a global public health problem with WHO South-East Asia Region accounting for about $45 \%$ of total cases. Tuberculosis is the ninth leading cause of death worldwide and is the leading infectious cause, ranking above HIV/AIDS. In 2016, about 1.3 million HIV negative people died due to tuberculosis [1]. However, Congenital Tuberculosis (CTB) is extremely rare condition with only less than 400 cases being reported thus far $[2,3]$. As the diagnosis and thus the treatment are often delayed, it has a mortality rate of almost $50 \%$ and about $22 \%$ in even those who receive treatment [4].

A TB in women of child-bearing age is commonly reported $[5,6]$. TB in pregnant women may involve either placenta or genital tract $[7,8]$ and often results in increased incidence of stillbirth, preterm delivery, and low birth weight deliveries [9]. Mode of transmission of tubercular bacilli to fetus in congenital tuberculosis is either by haematogenous route via the umbilical vein or is by infected amniotic fluid. In haematogenous transmission, foetal liver and lungs are primarily affected whereas ingestion or aspiration of infected amniotic fluid by babies either in utero, or during the delivery primarily affects foetal lungs and gut $[2,10]$. Congenital tuberculosis should be differentiated with perinatally acquired tuberculosis in which child is infected after delivery by a contagious source.

As clinical features of congenital tuberculosis are non-specific and often similar to other non-tubercular infections, it is extremely difficult to diagnoses and requires high index of suspicion. The affected newborn is frequently delivered premature, but clinical features suggestive of CTB is often delayed by several days or weeks with mean age at presentation being 24 days [11]. Child presents with non-specific signs and symptoms including refusal to feed, fever, irritability, lethargy, failure to gain weight, jaundice, lymphadenopathy, cough, and respiratory distress. Examination often reveals hepatosplenomegaly and abdominal distension. Child may also present with features of meningitis, septicaemia, persistant or recurrent pneumonia, disseminated intravascular coagulation. Ascitis, otitis media, parotitis, osteomyelitis, paravertebral abscess, cold abscess, and popular or pustular skin lesions are other infrequent presentations of CTB. In less than 10 per cent of cases children may present with apnoea, vomiting, cyanosis, jaundice, seizures and petechiae [2].

Diagnostic criteria for congenital tuberculosis were laid down by Beitzkiin 1935 and subsequently were revised by Cantwell [12] in 1994 Diagnostic criteria for congenital tuberculosis: Revised criteria by Cantwell [12] Proven tuberculosis lesions in the infant plus one of the following:

a. Lesions occurring in the first week of life.

b. A primary hepatic complex.

c. Maternal genital tract or placental tuberculosis.

d. Exclusion of postnatal transmission by thorough investigation of contacts.

Singh et al. [13] reported laboratory and clinical findings that may suggest congenital TB, which include a newborn from a TB endemic area with unresponsive worsening pneumonia, a mother with TB and a baby with nonspecific symptoms and the presence of hepatosplenomegaly and fever $[14,15]$.

\section{Investigation}

Congenital TB is difficult to diagnose and requires detailed antenatal history especially about maternal infection and needs high index of suspicion. The mothers of these children often appear healthy [12]. Mantoux test in CTB is often negative [3]. Chest X-ray and CT may show scattered infiltrates, bronchopneumonia, consolidation or periportal hypodensity [3]. Samples for isolation of tubercular bacilli from the infant for microscopy and culture could be obtained by gastric aspirates, induced sputum, bronchoalveolar lavage, tracheal aspirates, skin lesions, ear discharge, ascitic fluid, cerebrospinal fluid and pleural fluid. Liver and/or lymph node biopsy may also be done, when needed [2]. Newer modalities like Gene Xpert, LED flourescence microscopy and MGIT may yield faster results $[16,17]$. Indirect methods like rapid interferon gamma assays, Quanti FERON-TB Gold assay and T-SPOT using antigens ESAT-6, CFP-10 and TB7 may be used but are of limited value in newborns $[18,19]$. 


\section{Management}

No specific treatment regimen for congenital tuberculosis is advised by consensus. If and when congenital tuberculosis is suspected, appropriate samples should be sent for bacteriological and histological confirmation [3] and treatment should be started without waiting for the results. Treatment regimens should contain at least 2 and preferably 3 anti-tuberculosis drugs to which the organisms are likely to be susceptible. Standard treatment is Isoniazide (H), Rifampicin (R), Pyrizinamide (Z) and Streptomycin (S) /Ethambutol (E) for first 2 months followed by HR for 4 to 10 months [3]. Treatment regime of HRZ for total of 18 months along with intravenous amikacin during first 2 months often achieves complete recovery [3]. Other regimes used are HRZ with kanamycin/ amikacin for the first two months followed by HR for 6-12 months or similar to miliary tuberculosis [2]. These infants should be monitored throughout therapy but no consensus guidelines regarding the timing or the modes of monitoring exist, however X-ray and mantoux test have been advised at 6,12 and 24 weeks [2]. The prognosis depends upon early detection and appropriate treatment. Disease could be prevented through early detection of disease during pregnancy in mother and institution of appropriate therapy [3]. BCG vaccination protects against the disseminated and other severe form of tuberculosis, but in neonates with congenital tuberculosis there is no proven role of BCG vaccine.

\section{References}

1. (2017) Global tuberculosis Report 2017. World Health Organization, Geneva, Switzerland.

2. Mittal H, Das S, Faridi MM (2014) Management of new born infant born to mother suffering from tuberculosis: current recommendations \& gaps in knowledge. Indian J Med Res 140(1): 32-39.

3. Hassan G, Qureshi W, Kadri SM (2006) Congenital tuberculosis: JK Science 8(4): 193-194.

4. Manou Irmina S, Zhao D (2016) A perspective of the diagnosis and management of congenital tuberculosis. Journal of Pathogens 2016: 1-8.

5. Cantwell MF, Shehab ZM, Costello AM, Sands L, Green WF, et al. (1994) Brief report: congenital tuberculosis. N Engl J Med 330(15): 1051-1054.

6. Llewelyn M, Cropley I, Wilkinson RJ, Davidson RN (2000) Tuberculosis diagnosed during pregnancy: a prospective study from London. Thorax 55(2): 129-132.
7. Smith MHD, Teele DW (1990) Tuberculosis. In: Remington JS, Klein JO (Eds.), Infectious diseases of the fetus and newborn infant. ( $3^{\text {rd }}$ edn), WB Saunders, Philadelphia, USA, pp. 834-847.

8. Vallejo JG, Starke JR (1992) Tuberculosis and pregnancy. Clin Chest Med 13: 693-707.

9. Ormerod P (2001) Tuberculosis in pregnancy and the puerperium Thorax 56(6): 494-499.

10. Miller FJW (1982) Tuberculosis in children. Evolution, Epidemiology, Treatment, Prevention. ( $1^{\text {st }}$ edn), Churchill Livingstone, New Delhi, India, pp. 220-224.

11. Mony Vidya K, Jennifer P, Esther A, Iona M, Mariam S, et al. (2014) Congenital tuberculosis: a missed opportunity. Journal of the Pediatric Infectious Diseases Society 3(4): e45-e47.

12. Cantwell MF, Sehab ZM, Costello AM, Sands L, Green WF, et al. (1994) Brief report: congenital tuberculosis. New Engl J Med 330(15): 10511054.

13. Singh M, Kothur K, Dayal D, Kusuma S (2007) Perinatal tuberculosis: a case series. J Trop Pediatr 53: 135-138.

14. Lokesh T, Rajesh K (2017) Congenital tuberculosis with possible placental transmission and paradoxical reaction to anti-tuberculosis treatment. Lung Breath J 1(2): 1-2.

15. Abughali N, Vander KF, Annable W, Kumar ML (1994) Congenital tuberculosis. Pediatr Infect Dis J 13: 731-741.

16. Rossau R, Traore H, Beenhouwer H, Mijs W, Jannes G, et al. (1997) Evaluation of the INNO-LiPA Rif TB assay, a reverse hybridization assay for the simultaneous detection of Mycobacterium tuberculosis complex and its resistance to rifampin. Antimicrob Agents Chemother 41(10): 2093-2098.

17. World Health Organization (2011) Fluorescent light emitting diode (LED) microscopy for diagnosis of tuberculosis policy. Policy statement.

18. Mazurek GH, Villarino ME (2003) Guidelines for using the Quanti FERON-TB test for diagnosing latent Mycobacterium tuberculosis infection: Centers for Disease Control and Prevention. MMWR Recomm Rep 52(RR-2): 15-18.

19. Quezada CM, Kamanzi E, Mukamutara J, De Rijk P, Rigouts, et al. (2007) Implementation validation performed in Rawanda to determine whether the INNO-LiPA Rif. TB line probe assay can be used for detection of multidrug-resistant Mycobacterium tuberculosis in low-resource countries. J Clin Microbiol 45(9): 3111-3114.
Creative Commons Attribution 4.0 International License

For possible submissions Click Here
Submit Article

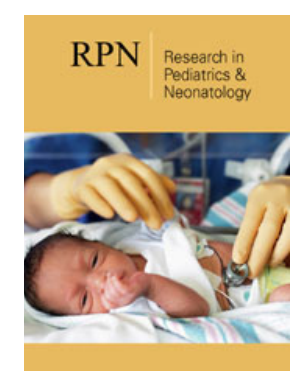

\section{Research in Pediatrics \& Neonatology}

\section{Benefits of Publishing with us}

- High-level peer review and editorial services

- Freely accessible online immediately upon publication

- Authors retain the copyright to their work

- Licensing it under a Creative Commons license

- Visibility through different online platforms 